\title{
Understanding selective trafficking of lymphocyte subsets
}

\author{
M Heydtmann, D H Adams
}

Bonzo/CXCR6 may be important in trafficking effector T cells making it a potential target for therapeutic modulation of inflammatory diseases

T his important study provides a mechanism to explain how different functional subsets of lymphocytes can be selectively recruited to tissue during an immune response by chemotactic cytokines (chemokines). The selective expression of particular chemokine receptors on subsets of lymphocytes allows these cells to be preferentially recruited to sites of inflammation. The authors report that a recently described chemokine receptor called Bonzo or CXCR6 is preferentially expressed on lymphocytes during their differentiation into type 1 effector cells, thereby linking the type 1/type 2 paradigm of immune responses with the burgeoning field of chemokines.

\section{REGULATION OF TYPE 1 AND TYPE 2 IMMUNE RESPONSES}

Cytokines produced by $\mathrm{T}$ (helper) cells are of critical importance in determining the outcome of many infectious and immune mediated diseases. The ability of the immune system to produce the appropriate set of cytokines in response to an infection and then to regulate that response as the infecting agent is cleared determines whether the response is successful and whether long term inflammatory damage persists. A crucial insight into how cytokines coordinate immune responses was provided by the characterisation of $\mathrm{T}$ cells into functional subsets ${ }^{1}$ : type $1 \mathrm{~T}$ cells, which are driven by interleukin 12, and dominated by interferon $\gamma($ IFN- $\gamma)$ secretion and cell mediated immunity; and type $2 \mathrm{~T}$ cells, which are associated with interleukin 4 production and humoral immunity. Originally established on the basis of different cytokines produced by $\mathrm{T}$ helper (Th) cell clones, it is now clear that this concept defines distinct immune pathways that affect most, if not all, cells of the immune system and hence the nomenclature $\mathrm{Tl}$ and $\mathrm{T} 2$ is more accurate.

In many circumstances both $\mathrm{T} 1$ and $\mathrm{T} 2$ responses are required at different time points to effectively eradicate an infectious agent, and the T1/T2 dichotomy is an oversimplification, albeit a useful one for analysing immune responses. However, some infections are dominated by one response, for example leishmaniasis, in which $\mathrm{Tl}$ responses are required for clearance of the infection, and helminths in which $\mathrm{T} 2$ responses are required to

Kim CH, Kunkel EJ, Boisvert J, et al. Bonzo/CXCR6 expression defines type 1-polarized T-cell subsets with extralymphoid tissue homing potential. J Clin Invest $2001 ; 107: 595-601$

Abstract: Chemokine receptor expression is finely controlled during T-cell development. We show that newly identified chemokine receptor Bonzo/CXCR6 is expressed by subsets of Th1 or T-cytotoxic 1 (Tc1) cells, but not by Th2 or Tc2 cells, establishing Bonzo as a differential marker of polarized type $1 \mathrm{~T}$ cells in vitro and in vivo. Priming of naive T cells by dendritic cells induces expression of Bonzo on T cells. IL-12 enhances this dendritic cell-dependent upregulation, while IL-4 inhibits it. In blood, 35-56\% of Bonzo+ CD4 T cells are Th1 cells, and $60-65 \%$ of Bonzo+ CD8 T cells are Tcl cells, while few Bonzo+ cells are type 2 T cells. Almost all Bonzo+ Tcl cells contain preformed granzyme A and display cytotoxic effector phenotype. Most Bonzo+ T cells lack L-selectin and/or CCR7, homing receptors for lymphoid tissues. Instead, Bonzo+ T cells are dramatically enriched among $T$ cells in tissue sites of inflammation, such as rheumatoid joints and inflamed livers. Bonzo may be important in trafficking of effector T cells that mediate type 1 inflammation, making it a potential target for therapeutic modulation of inflammatory diseases.

control and eliminate gastrointestinal infestation. Type 1 responses are believed to be critical for clearance of many viruses, including hepatitis $\mathrm{B}$ and $\mathrm{C}$ viruses. The characteristic type 1 cytokines, IFN- $\gamma$ and tumour necrosis factor $\alpha$ (TNF- $\alpha$ ), have also been shown to play a role in the pathogenesis of a number of autoimmune and inflammatory disorders. In the normal human ileum, jejunum, and colon, intraepithelial lymphocytes produce type 1 cytokines and display cytolytic activity. ${ }^{2}$ In inflammatory bowel disease (IBD), especially Crohn's disease, there is evidence of an excessive type 1 response with elevated production of IFN- $\gamma$ and increased numbers of IFN- $\gamma$ secreting cells which is also found in murine IBD models. ${ }^{3}$ The successful therapeutic use of anti-TNF- $\alpha$ antibodies in Crohn's disease underscores this. Although the signals that drive differentiation into type 1 or type 2 responses in vitro are known, until recently it has been unclear as to how type 1 effector cells can be selectively recruited to a site of infection or inflammatory damage. The current paper suggests that a novel chemokine receptor, Bonzo or CXCLl6, defines type 1 effector lymphocytes and allows them to interact with the chemokine CXCR16 and thereby to be selectively recruited to tissue.

\section{CHEMOKINES AND CHEMOKINE RECEPTORS}

Chemokines are 8-12 kDa heparin binding cytokines with the ability to attract leucocyte subsets to specific sites. More than 50 human chemokines have been identified and are classified according to the arrangement of conserved cysteine residues into four groups: $\mathrm{CXC}, \mathrm{CC}, \mathrm{C}$, and $\mathrm{CX} 3 \mathrm{C}$. Chemokines activate seven transmembrane spanning, $G$ protein linked receptors resulting in activation of downstream signals that determine the response in a given cell. In most circumstances the result is cytoskeletal rearrangement and changes in motility as a consequence of phospholipase $\mathrm{C}$ and Rho activation, although activation of protein tyrosine kinases can, under particular circumstances, lead to cell activation and proliferation. ${ }^{5}$ Most chemokine receptors bind several chemokines although some are specific for a single chemokine and two nonsignalling receptors, the Duffy antigen on erythrocytes and heparan sulphate proteoglycans in the glycocalyx and extracellular matrix, bind multiple chemokines via low affinity interactions to retain them at specific sites. ${ }^{6}$

The most important function attributed to chemokines is their ability to regulate leucocyte recruitment, retention, and positioning in tissue. They do this not only by stimulating directional migration but also by activating leucocyte integrins to bind to other cells and the extracellular matrix. Critical roles for chemokines have been demonstrated in the recruitment and retention of stem cells in bone marrow, thymocytes during $\mathrm{T}$ cell differentiation in the thymus, and 
dendritic cells in lymph nodes, as well as the control of effector cell recruitment to sites of infection or tissue damage. Chemokines can be usefully subdivided into two functional groups: inducible chemokines, produced in response to inflammation that recruit leucocytes, dendritic cells, and activated T cells; and constitutive chemokines expressed in the bone marrow, thymus, and secondary lymphoid organs that regulate physiological leucocyte trafficking. ${ }^{6}$ Regulation of leucocyte recruitment is complex and involves both secretion and presentation of chemokines in the target tissues and regulated expression of chemokine receptors on leucocytes during differentiation and activation. For example, naïve $\mathrm{T}$ cells which traffic from blood to lymph nodes express low levels of the inflammatory chemokine receptors CXCR3 and CCR5 but high levels of CCR7 which allows them to respond to the constitutive chemokine SLC, expression of which is largely confined to secondary lymphoid tissue. After activation by antigen in lymph nodes, naïve $\mathrm{T}$ cells undergo differentiation into effector cells and downregulate CCR7 while increasing expression of CXCR3 and CCR5, a phenotypic change which effectively excludes them from lymph nodes but allows them to be readily recruited to inflamed tissue where inflammatory chemokines that activate CXCR3 (IP-10, Mig, and ITAC) and CCR5 (RANTES, MIP- $1 \alpha$, and MIP-1 $\beta$ ) are expressed.

\section{CHEMOKINES AND THE REGULATION OF TYPE 1/TYPE 2 IMMUNE RESPONSES}

Chemokines are important components of polarised type 1 and type 2 responses and act at several points during $\mathrm{T}$ cell differentiation. They can have direct effects on $\mathrm{T}$ cell activation as well as altering the migratory potential of the $\mathrm{T}$ cell and thereby altering where it goes and which cell it interacts with. In addition, dendritic cells (DCs), which are responsible for $\mathrm{T}$ cell activation and polarity of cytokine secretion, are also affected by chemokines both in terms of the type and number of DCs that are recruited to a site of inflammation and in terms of how the DC responds to activation. Thus signals delivered to DCs via CCR5 can drive IL-12 secretion whereas signals delivered via CCR2 inhibit IL- $12^{\circ}$ and these ${ }^{9}$ cytokines will define the subsequent $\mathrm{T}$ cell differentiation. Finally, the chemokine receptors expressed by effector $\mathrm{T}$ cells determine where these cells migrate. The complexity of these processes is illustrated by the results of studying immune responses in genetically modified animals in which chemokines or their receptors are either over expressed or deleted. Disrupting chemokines or chemokine receptors has pro- duced unpredicted results which vary depending on the type of inflammatory model studied and at what stage during the evolution of the process the chemokine is inhibited. ${ }^{10-13}$

The present paper concentrates on the role of a novel chemokine CXCL16 in driving the recruitment of type 1 effector cells into tissue. Polarised $\mathrm{T} 1$ and $\mathrm{T} 2$ populations (characterised by production of IFN- $\gamma$ and IL-4, respectively) have been shown to display distinct chemokine receptor profiles in vitro ${ }^{14}$ with Thl cells expressing CXCR3 and CCR5 allowing them to respond to the IFN inducible chemokines ITAC, IP10, and Mig (CXCL9, CXCL10, and CXCL11) ${ }^{15}$ and the CCR5 ligands RANTES, MIP- $1 \alpha$, and MIP- $\beta$. Conversely, the CC chemokines, macrophage derived chemokine (MDC, CCL22) and thymus and activation regulated chemokine (TARC, CCL17), are preferential attractants for polarised type 2 cells that express CCR4 and CCR3. ${ }^{16}$ MDC production is induced by IL-4 and IL- 13 and inhibited by IFN- $\gamma$ and IL- 12 . There is also evidence for bilateral regulation because chemokines that attract type 1 cells via CXCR3 can concomitantly block the migration of type 2 cells in response to CCR3 ligands thus enhancing the polarisation of $\mathrm{T}$ cell recruitment. ${ }^{17}$ These and other studies have outlined the existence of chemokine based circuits that induce and sustain polarised type 1 and type 2 responses.

Recently, a new CXC chemokine, $\mathrm{CXCLl}^{18}{ }^{19}$ which binds to the receptor CXCR6 (Bonzo), was described. CXCL16 is unique among the $\mathrm{CC}$ and $\mathrm{CXC}$ chemokines in being a transmembrane protein. It was initially thought to be involved in CD8-dendritic cell interactions based on its expression on naïve CD8 $\mathrm{T}$ cells in mice but it appears that functional CXCR6 is absent from naïve T cells in humans making this an unlikely role in humans. A recent study ${ }^{20}$ showed that regulation of CXCR6 on lymphocytes parallels that of CCR5 and is inversely correlated with CXCR4, further evidence of a role for CXCR6 in type 1 responses..$^{21}$ Interestingly, the only other known transmembrane chemokine CX3CLl (Fractalkine) is also found to be preferentially expressed by type $1 \mathrm{com}$ pared with type $2 \mathrm{~T}$ cells. ${ }^{22} \mathrm{Kim}$ et al have now extended these observations to demonstrate that CXCR6 expression is upregulated on $\mathrm{T}$ cells by interactions with dendritic cells and that the addition of IL-12 enhances the generation of CXCR6 $^{+}$cells whereas IL-4 reduces it. Furthermore, most of the $\mathrm{CXCR6}^{+}$cells in blood are IFN- $\gamma$ secreting helper $\mathrm{T}$ cells, cytotoxic $\mathrm{T}$ cells, or $\mathrm{CD} 56^{+} \mathrm{T}$ cells that are enriched for effector functions and IFN- $\gamma$ release. Thus upregulation of CXCR6 on primed T cells by DCs in an IL-12 rich environment will lead to the release of effector cells with the potential to mediate type 1 responses. In order to complete the story, the authors describe enrichment of CXCR6 cells in inflamed tissue implying the receptor is involved in effector cell recruitment to or retention in tissue. If this model is correct, further characterisation of the CXCR6 ${ }^{+} \mathrm{T}$ cells in specific diseases is of great importance. Their potential to mediate effector functions may be beneficial in infectious diseases where it is likely that $\mathrm{CXCR6}^{+}$cells include a high proportion of virus specific $\mathrm{T}$ cells in, for instance, chronic viral hepatitis. However, the same effector cells could lead to inappropriate recruitment and tissue damage in type 1 autoimmune disorders, as suggested by the finding that $\mathrm{CXCR} 6^{+} \mathrm{T}$ cells are enriched in the joint in rheumatoid arthritis. The fact that circulating CXCR6 $^{+} \mathrm{T}$ cells include $\alpha 4 \beta 7^{+}$cells suggests they could also be recruited to the gut in IBD. CXCR6 and CXCL16 therefore become interesting therapeutic targets and provoke a dualistic approach to immune modulation. Whereas neutralisation of $\mathrm{CXCR}^{+}{ }^{+}$effector cells might be expected to be beneficial in type 1 driven immune mediated diseases such as rheumatoid arthritis and Crohn's disease, enhancement of these cells by either selective activation in vivo or adoptive transfer may promote antiviral responses in patients with chronic viral hepatitis. It would appear that it is not yet bedtime for Bonzo.

Gut 2002;50:150-152

\section{Authors' affiliations}

M Heydtmann, D H Adams, Liver Research Laboratories, MRC Centre for Immune Regulation, University of Birmingham Institute for Clinical Science, Queen Elizabeth Hospital, Edgbaston, Birmingham B 15 2TH; email: d.h.adams@bham.ac.uk

MH holds a Clinical Training Fellowship from the Wellcome Trust.

\section{REFERENCES}

1 Mosmann TR, Cherwinski $\mathrm{H}$, Bond MW, et al. Two types of murine helper T cell clone. I. Definition according to profiles of lymphokine activities and secreted proteins. J Immunol 1986; 136:2348-57

2 Nagata S, McKenzie C, Pender SL, et al. Human Peyer's patch T cells are sensitized to dietary antigen and display a Th cell type 1 cytokine profile. J Immunol 2000;165:531521.

3 Groux H, Powrie F. Regulatory T cells and inflammatory bowel disease. Immunol Today 1999;20:442-5

4 Powrie F. T cells in inflammatory bowel disease: protective and pathogenic roles. Immunity 1995; 3:171-4.

5 Sotsios Y, Ward SG. Phosphoinositide 3-kinase: a key biochemical signal for cell migration in response to chemokines. Immunol Rev 2000;177:217-35.

6 Murdoch C, Finn A. Chemokine receptors and their role in inflammation and infectious diseases. Blood 2000;95:3032-43.

7 Moser B, Loetscher P. Lymphocyte traffic control by chemokines. Nat Immunol 2001;2:123-8. 
8 Luther SA, Cyster JG. Chemokines as regulators of T cell differentiation. Nat Immunol 2001;2:102-7

9 Matsukawa A, Lukacs NW, Standiford TJ, et al. Adenoviral-mediated overexpression of monocyte chemoattractant protein-1 differentially alters the development of Th 1 and Th2 type responses in vivo. J Immunol 2000; 164: 1699-704.

10 Chensue SW, Lukacs NW, Yang TY, et al. Aberrant in vivo T helper type 2 cell response and impaired eosinophil recruitment in CC chemokine receptor 8 knockout mice. J Exp Med 2001;193:573-84

11 Shang $X$ Qiu B, Frait KA et al Chemokine receptor 1 knockout abrogates natural killer cell recruitment and impairs type- 1 cytokines in lymphoid tissue during pulmonary granuloma formation. Am J Pathol 2000; 157:2055-63

12 Boring L, Gosling J, Chensue SW, et al. Impaired monocyte migration and reduced type 1 (Th 1) cytokine responses in C-C chemokine receptor 2 knockout mice. J Clin Invest 1997;100:2552-61.
13 Topham PS, Csizmadia V, Soler D, et al. Lack of chemokine receptor CCR 1 enhances Th 1 responses and glomerular injury during nephrotoxic nephritis. J Clin Invest 1999:104: 1549-57.

14 Sallusto F, Lanzavecchia A, Mackay CR Chemokines and chemokine receptors in T-cell priming and Th 1/Th2-mediated responses. Immunol Today 1998;19:568-74.

15 Shields PL, Morland CM, Salmon M, et al. Chemokine and chemokine receptor

interactions provide a mechanism for selective $T$ cell recruitment to specific liver compartments within hepatitis $C$ infected liver. $\mathrm{J}$ Immunol 1999;163:6236-43.

16 Bonecchi R, Bianchi G, Bordignon PP, et al. Differential expression of chemokine receptors and chemotactic responsiveness of type $1 \mathrm{~T}$ helper cells (Th 1s) and Th2s. J Exp Med 1998;187:129-34.

17 Loetscher P, Pellegrino A, Gong JH, et al. The ligands of CXC chemokine receptor 3 , I-TAC, Mig and IP10, are natural antagonists for CCR3. J Biol Chem 2000;276:2986-91.
18 Matloubian M, David A, Engel S, et al. A transmembrane CXC chemokine is a ligand for HIV-coreceptor Bonzo. Nat Immunol 2000;1:298-304.

19 Wilbanks A, Zondlo SC, Murphy K, et al. Expression cloning of the STRL33/BONZO/ TYMSTR ligand reveals elements of CC, CXC and $\mathrm{CX} 3 \mathrm{C}$ chemokines. J Immunol 2001;166:5145-54

20 Unutmaz D, Xiang W, Sunshine $\mathrm{W}$, et al. The primate lentiviral receptor Bonzo/STRL33 is coordinately regulated with CCR5 and its expression pattern is conserved between human and mouse. J Immunol 2000; 165:3284-92.

21 Jagodzinski PP, Trzeciak WH. Differentia expression of chemokine receptor CXCR4 in Th1 and Th2 subtypes of CD4+ lymphocytes. Folia Histochem Cytobiol 2000;38:21-3.

22 Fraticelli P, Sironi M, Bianchi G, et al. Fractalkine (CX3CL1) as an amplification circuit of polarized Th1 responses. J Clin Invest 2001;107:1173-81.

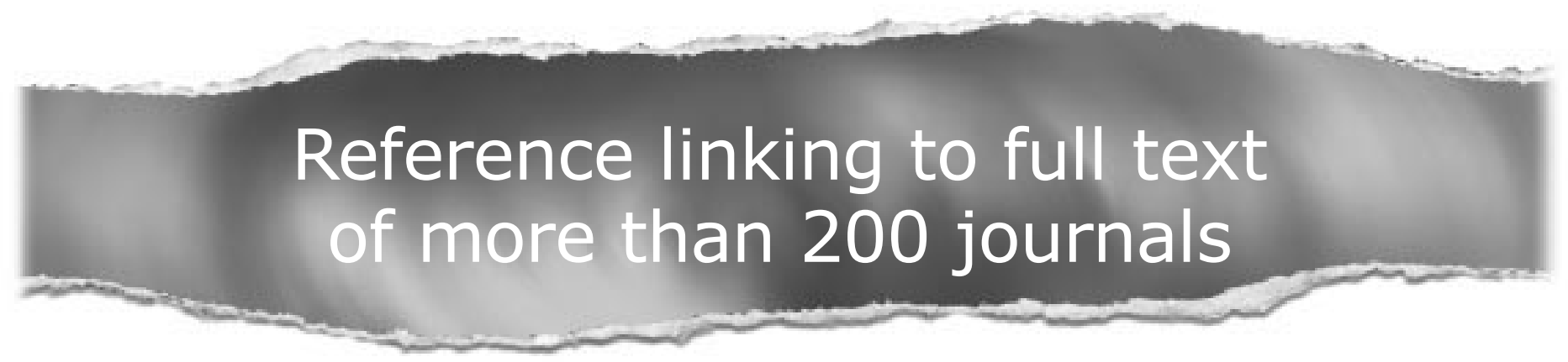

\section{Toll free links}

You can access the FULL TEXT of articles cited in Gut online if the citation is to one of the more than 200 journals hosted by HighWire (http://highwire.stanford.edu) without a subscription to that journal. There are also direct links from references to the Medline abstract for other titles.

www.gutjinl.com 